\title{
Social and health sector reform towards 2040 in Japan
}

\author{
Tomonori Hasegawa, Kunichika Matsumoto, Ryo Onishi and \\ Koki Hirata \\ Toho University, Tokyo, Japan
}

\begin{abstract}
Purpose - The purpose of this paper is to examine the health sector reform toward 2040 of Japan as a super-aged society.

Design/methodology/approach - This paper discusses the current healthcare policies adopted in Japan and projects the challenges in future as a super-aged society.

Findings - Through Japanese experiences, it is considered that Community-based Integrated Care System is useful, which takes into account the perspective of health care users. Being a super-aged society, it is essential for Japan to have more consensus by further removing obstacles, and paying attention to the change of paradigm and the purpose of care.

Originality/value - Based on the case of Japan, this paper serves as a reference for other East Asian countries, which would sooner or later encounter the similar situation of becoming super-aged societies in the $21^{\text {st }}$ century.
\end{abstract}

Keywords Health sector reform, Community-based integrated care system, Super-aged society, Japan Paper type Viewpoint

\section{Introduction}

Japan has implemented health sector reform to enable the maintenance of a healthcare supply system in times of low economic growth and rapid aging, which the world has never experienced before. A new medical and long-term care (LTC) framework for a super-aged society has been created; however, there are still many problems to be solved before 2040, when the absolute number of the elderly population is expected to peak. Currently, the Japanese government is reforming the social security system, aiming for 2040 (Ministry of Health, Labour and Welfare, 2018a).

In other East Asian countries, as in Japan, society is aging rapidly, and health sector reform has become an urgent issue. In 2007, Japan's aging rate exceeded 21 percent for the first time in the world (the so-called "super-aged society"). According to an estimation from the United Nations, South Korea will enter the super-aged society in 2027, Singapore in 2028, Thailand in 2033, China in 2035, and Vietnam in 2050 (United Nations, 2019). In this context, examining health sector reform in Japan, regardless of its success or failure, is considered beneficial for those East Asian countries that will become super-aged societies following Japan.

The authors first review the trends of health sector reform in Japan from the mid-1980s to the present, noting the background in which the reform was implemented. Then, the existing problems occurring in the aging of Japan are discussed. Based on those considerations, the issues for preparing a healthcare system for 2040 and what can be learnt from the Japanese experience will be summarized.

(C) Tomonori Hasegawa, Kunichika Matsumoto, Ryo Onishi and Koki Hirata. Published in Public Administration and Policy. Published by Emerald Publishing Limited. This article is published under the Creative Commons Attribution (CC BY 4.0) licence. Anyone may reproduce, distribute, translate and create derivative works of this article (for both commercial and non-commercial purposes), subject to full attribution to the original publication and authors. The full terms of this licence may be seen at http:// creativecommons.org/licences/by/4.0/legalcode
Received 23 June 2020

Revised 15 August 2020 Accepted 6 September 2020
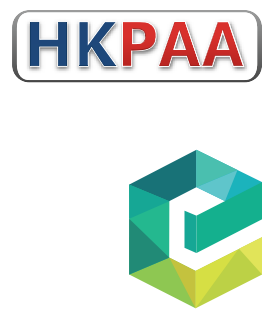

Public Administration and Policy Vol. 23 No. 3,2020 pp. 259-271 phish Limite DOI 10.1108/PAP-06-2020-0030 


\section{Review of health sector reform}

With the introduction of the universal health coverage insurance system in 1961, medical demand increased significantly in Japan. However, after the two oil shocks (the first in 1973, and the second in 1979), when high economic growth came to an end, policy shifts were implemented to curb medical expenses. In the mid-1980s, when Yasuhiro Nakasone became Prime Minister (1982-1987), the Elderly Health Law was enacted, and the Medical Care Act, which had never been revised since its enactment in 1948, was amended. The Elderly Health Law removed elderly people aged 70 and older from the existing medical insurance system, and put them under a new system, in which financial resources are provided by each medical insurer (regional/occupational insurance). Moreover, free (of copayment) medical care service for the elderly since 1973 has come to an end (Hasegawa, 2020).

The revision of the Medical Care Act (the first amendment) initiated a Regional Medical Plan. This amendment aimed to allocate appropriate resources and resolve the uneven distribution of acute care hospitals as the healthcare market expanded, and prefectures came to play a major role in creating a Regional Medical Plan. In the Regional Medical Plan, prefectures established medical areas (secondary medical areas) to provide general medical services and set the upper limit for the number of beds in each medical area. Construction of new hospitals is only allowed in secondary medical areas in which the number of existing beds is below the upper limit. Although this plan set an upper limit on the number of new beds added, existing hospitals were not forced to reduce beds. This approach served to facilitate consensus among stakeholders such as hospital owners regarding Regional Medical Plans.

These Regional Medical Plans are to be revised by the prefectures at least once every five years, and the setting of secondary medical areas is also revised. A major change in the overall Regional Medical Plan was implemented in the fifth revision, and a new plan came to play a role in establishing a healthcare delivery system for each of four diseases and five medical services. The four diseases are cancer, stroke, acute myocardial infarction, and diabetes; the five medical services are emergency care, disaster medical care, medical care for remote areas, perinatal medical care, and pediatric medical care (including emergency pediatric medical care). Mental diseases and home health care have been added, and the construction of a cooperative medical system to provide for the five diseases, five medical services, and home health care is being promoted. The five diseases were selected based upon their burden on society, and the five medical services were selected given they were important issues in securing regional medical care. Prefectural governments should: (1) clarify "necessary medical functions"; (2) specify "the names of the medical institutions that perform each medical function"; and (3) set "the numerical targets" in their Regional Medical Plans according to the actual situation of each region, such as patient trends and medical resources. The medical plan is created by each prefecture independently and does not provide medical services at a uniform level nationwide (Ministry of Health, Labour and Welfare, 2012). However, this revision means that quantitative medical planning, such as bed regulation, has changed to a medical plan focusing on quality.

On the other hand, along with the development of the medical provision system, LTC services have become important. The post-Nakasone Cabinet Japanese government had been preparing for an upcoming aging society, and the 10-year General Strategy for the Promotion of Health and Welfare for the Elderly (Gold Plan), formulated in 1989, included the provision of special elderly nursing homes, home helpers, day services, and short stays. The New Gold Plan, launched in 1995, has implemented a plan for securing human resources for LTC, aiming to create 170,000 home helpers (Ministry of Health, Labour and Welfare, 2002).

Until then, LTC for the elderly was expected to be provided in each household, and LTC was considered within the framework of welfare. In 2000, LTC insurance was introduced with the aim of socializing LTC (Ministry of Health, Labour and Welfare, 2002). After the introduction of LTC insurance, the demand for LTC increased, and from 2000 to 2015, 
the number of insured persons aged 65 years or older increased from 21.65 million to 33.08 million (1.53 times); the number of persons with care need and support need certification increased from 2.18 million to 6.08 million (2.79 times); home health care users increased from 0.97 million to 3.82 million (3.94 times); facility service users increased from 0.52 million to 0.90 million (1.73 times); and the total number of users increased from 1.49 million to 5.11 million (3.43 times).

With the expansion of medical services and LTC services, national medical expenses have increased. Figure 1 shows the growth in national medical expenses and its share of GDP from 1955 to 2016. Until the introduction of LTC insurance, national medical expenses included LTC expenses; thus, the LTC insurance payments are shown from 2000 onward. Healthcare expenditures, including LTC insurance payments, have increased at approximately the same rate since the 1970 s.

Although the demand for medical and LTC services has increased significantly, Japan is currently in a phase of population decline. The young population and the working-age population are declining, and the demand for medical services in the acute phase will decrease at first. The elderly population over the age of 65 peaks in approximately 2040 and is expected to decrease thereafter. In other words, in the future, the market for medical services, which has expanded thus far, will be shrinking. In light of these future changes in the demographic structure, the Regional Medical Vision was created in 2015 (Ministry of Health, Labour and Welfare, 2015). The goals of the Regional Medical Vision are to redistribute hospital beds (from the supplier's perspective), to reduce the total number of beds, and to convert beds from acute care to recovery/chronic care. Based on the population structure in 2025 and the inpatient and outpatient rates in 2013, the estimated medical care demand can be calculated and, the redistribution/reduction of beds can be planned. Prefectures are expected to play a key role in facilitating cooperation among hospitals with financial incentives. Voluntary adjustment of hospital beds/functions mediated by prefectures is expected. However, it is difficult for hospital administrators to imagine a shrinking market, and society's traditional

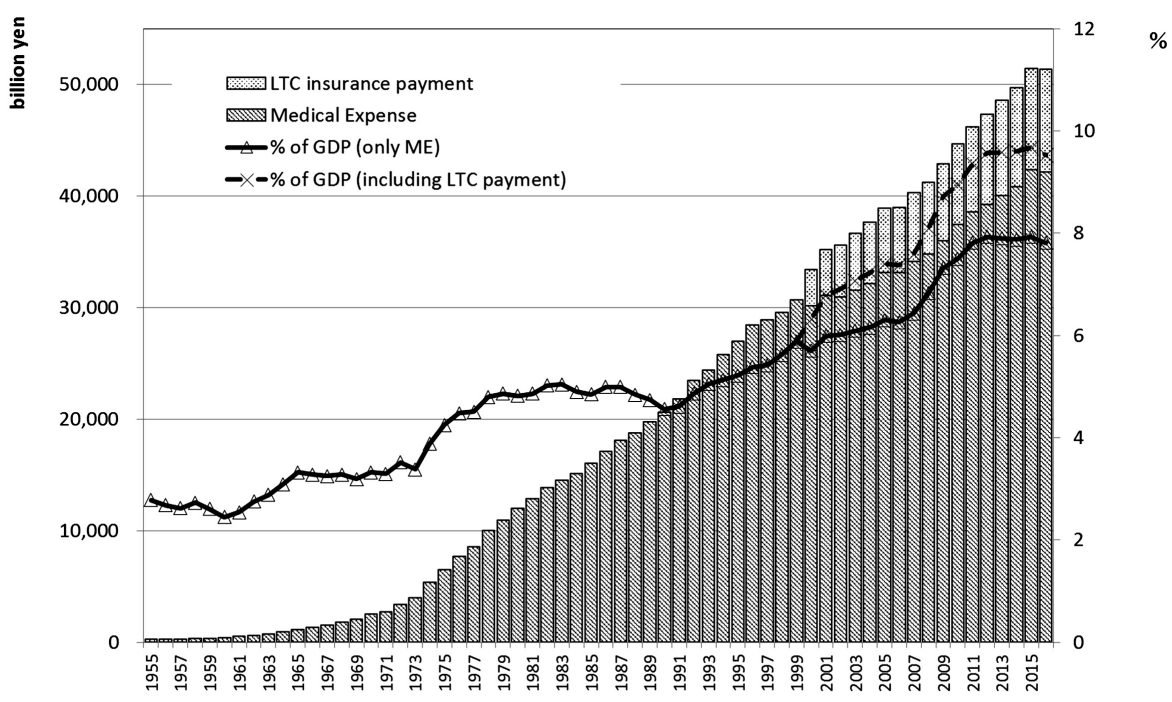

Source: Ministry of Health, Labour and Welfare (2019a); Ministry of Health, Labour and Welfare (2017a)

Figure 1. Healthcare expenditure trends 
PAP

23,3

262

medical culture was likely to regard chronic care as different from what had been taught, given chronic care recently began to attract attention. In fact, almost all university teaching hospitals are acute care hospitals, and few universities provide chronic care teaching programs for young doctors. Hospital administrators have hesitated to move to chronic beds. Prefectures have only a coordinating function, with no power to enforce changes. Therefore, compared with the Regional Medical Plan, the Regional Medical Vision has less power and is likely to have a difficult time with implementation.

Medical care and LTC for the elderly must be closely linked instead of separate entities. The Community-based Integrated Care System was proposed in 2016 to build a care system in which five services (housing, prevention, and life support, in addition to medical care and LTC services) can be provided simultaneously in the area where the elderly live (Figure 2). The Community-based Integrated Care System is intended to establish a system that matches the local situation and its characteristics (Morikawa, 2014; Song and Tang, 2019). Each municipality (there are 1,741 municipalities) plans the care system with its own aims, focusing on health care users rather than nationwide common aims. This system is created by each municipality according to the local situation, and many cases are open to the public by the Ministry of Health, Labour and Welfare (Ministry of Health, Labour and Welfare, 2016). In this system, four principles are proposed: self-help, mutual-help, help by social insurance, and help by social safety net. This system assigns a mid-sized hospital to support daily life, including home health care.

The Japanese experience until 2016 has taught us that care must be integrated, that the perspective of the health care user is important, that the culture of a medical society is important and sometimes difficult to change, and that establishing consensus is difficult but essential. The COVID-19 pandemic in 2020 revealed the presence of significant number of vulnerable populations in a super-aged society, and the outbreak in elderly care facilities can

Figure 2.

Community-based Integrated Care System model

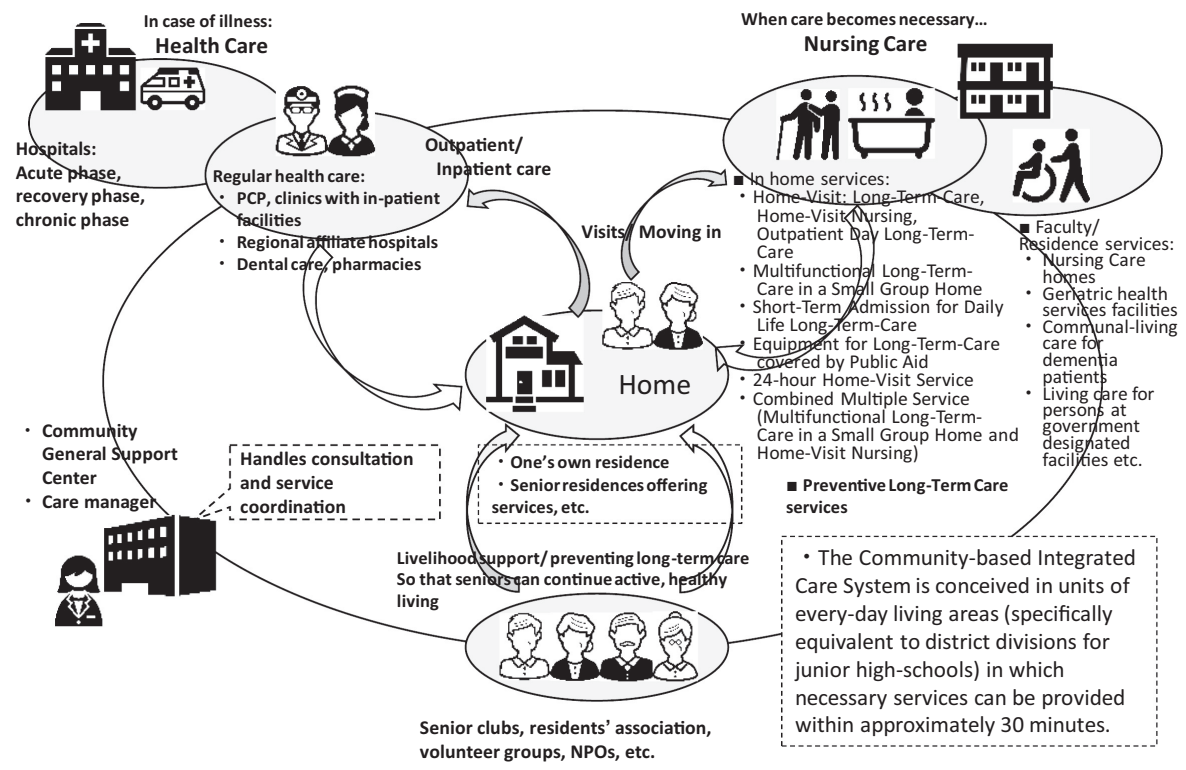

Source: Adapted from Ministry of Health, Labour and Welfare (2017b) 
be disastrous. Local governments including prefectures and municipalities were forced to support hospitals and elderly care facilities taking the local needs into account. Infection control may be included in the Regional Medical Plan in near future, and local governments would be willing to play an important role in healthcare delivery.

\section{Current condition of aging in Japan}

Table 1 summarizes statistics on the aging situation in Japan. The Japanese population is already in a phase of decline. The elderly population had risen to 28.1 percent by 2018 (compared with 5.0 percent in 1950), the highest among the OECD countries (Figure 3) (Cabinet Office, 2019). Life expectancy has also increased to 81.1 years for men and 87.3 years for women (2017). One of the salient features of Japan's aging population is that the speed of aging was extremely fast. Development from an aging society (aging rate of 7 percent) to an aged society (aging rate of 14 percent) took only 25 years, from 1970 to 1995; much faster than France (115 years), Sweden (85 years), Germany (40 years), or the UK (47 years) (United Nations, 2015). This process, of course, has been accompanied by an increase in life expectancy; however, the effect of the declining birthrate is significant. The total fertility rate, which was 4.32 in 1948, was 1.43 in 2018. In addition, strict limitation of immigration - foreigners living in Japan account for only 2.2 percent of the total population in 2019 according to Ministry of Justice (2019) - has also contributed to Japan's rapid aging, given immigrants are generally young and their total fertility rate is high. If this trend continues, an even more significant aging problem is expected by 2025 , when the baby boomers (born in 1947-1949) will enter the old-old stage, and in 2040, when the second baby boomers (born in 1971-1974) will enter the old-old stage.

Regarding the causes of death, the top 3 causes are malignant neoplasms, heart diseases, and cerebrovascular diseases. The average age of death in these diseases is also increasing. The number of hospitals has been declining, with 8,372 in 2018. In addition, the average length of hospital stay in acute care beds, which was once considered to be very long, has been shortened due to progress in the division of bed function. It was 16.2 days in 2017 (Table 1).

In addition to the aging of society, the family structure has also been changing. Figure 4 shows the trend of the number of households and the number of household members in Japan. Senior citizen households have also been increasing: single elderly account for 11.1 percent, and elderly couples account for 9.8 percent of all households. Such a reduction in the number of household members and an increase in the number of senior citizen households have led to a great decline in the ability to care for the elderly at home. The problem of 'elderly care by the

Population

Aging rate ( $\%$ of $65+$ population)

Total Fertility Rate

Life expectancy

Leading cause of death

National medical care expenditure

Number of hospitals

Average length of stay
126.2 million $\left(-0.22 \%\right.$ from the previous year) $(2019)^{1)}$

$28.1 \%$ (under 15: $12.2 \%, 15-64: 59.7 \%$ ) $(2018)^{1)}$

$1.43(2018)^{2)}$

male 81.1 years old, female 87.3 years old $(2017)^{3)}$

1. malignant neoplasm, 2. heart disease, $3 . \mathrm{CVD}^{2)}$

4,213 billion yen $(7.81 \%$ of GDP) + LTC expenditure 9,229 billion yen $\left(1.72 \%\right.$ of GDP) $(2016)^{4)}$

$8,372(2018)^{5)}$

16.2 days $(2017)^{6)}$

Notes: 1) Population Estimates, 2) Vital Statistics, 3) Life Tables, 4) Estimates of National Medical Care Expenditure, 5) Survey of Medical Institutions, 6) Hospital Report

Source: Statistics Bureau, Ministry of Internal Affairs and Communications with collaboration of Ministries and Agencies (2020)

Table 1.

Aging situation in Japan 
\begin{tabular}{l} 
PAP \\
23,3 \\
$\mathbf{2 6 4}$ \\
\hline
\end{tabular}

Figure 3.

Percentage of population aged 65 and older

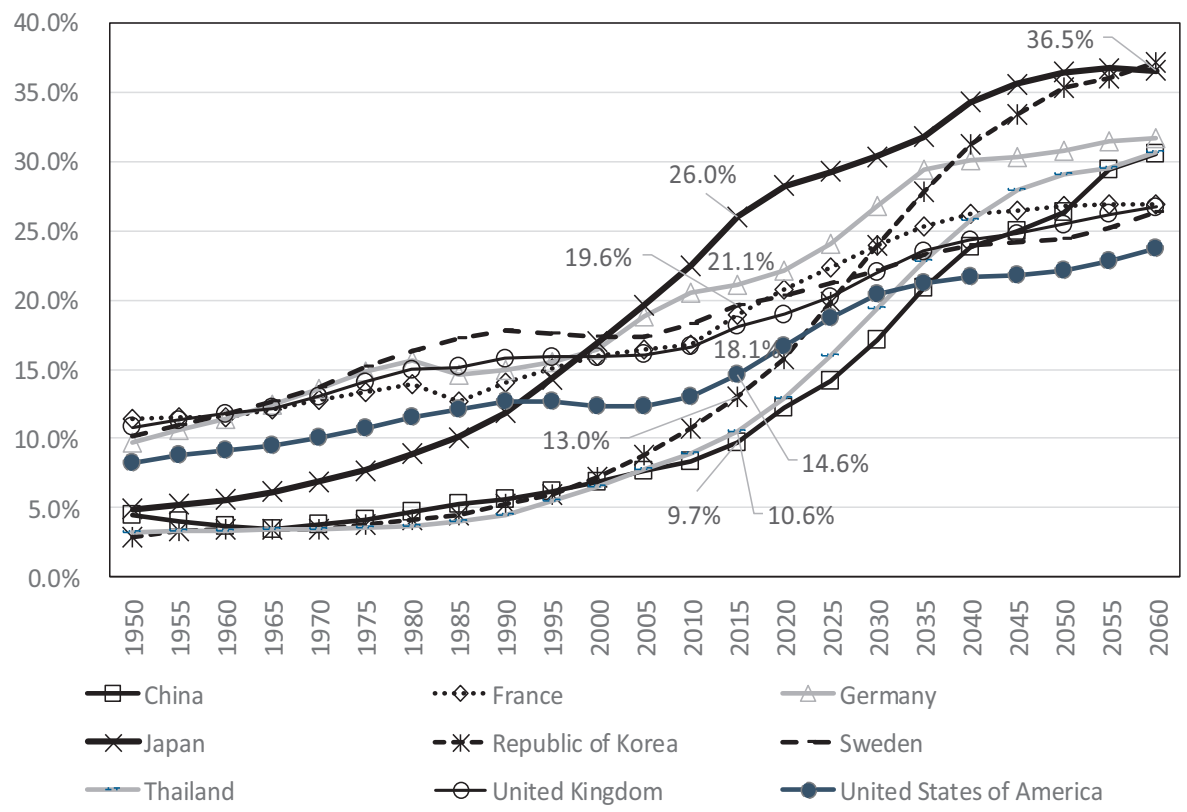

Source: United Nations (2019)
Figure 4 .

Trend of number of households and household members

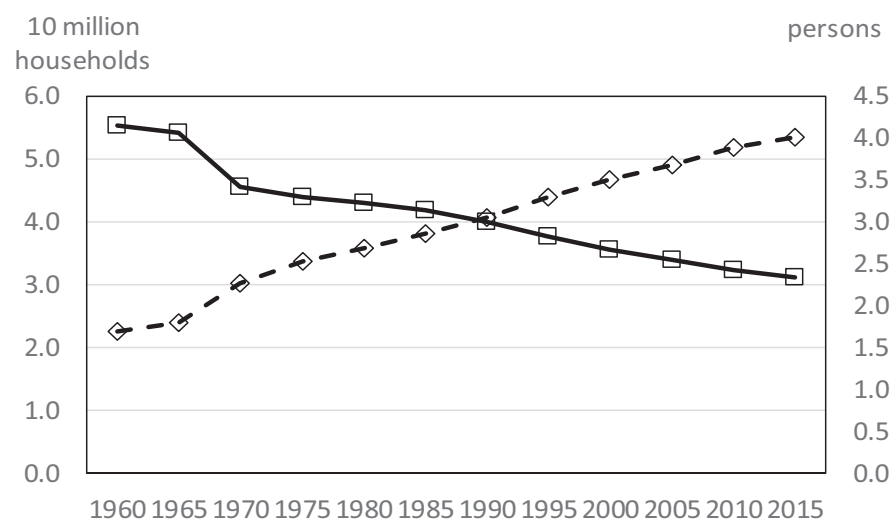

$-\diamond$ The number of households
$\leftarrow$ The number of household members (right axis)

Source: Ministry of Internal Affairs and Communication (2016)

elderly' and the problem of care for the elderly with dementia by the other elderly with dementia are increasing.

As shown in Figure 1, medical expenses and LTC expenses have risen in response to such aging, but the use of medical and LTC services is also biased toward the elderly. In regard to 
medical expenses in 2017, elderly people (older than 65 years), which account for 27.7 percent of the population, use 62.4 percent of the medical expenses. Thus, medical expense per capita of those older than 65 years is more than 4 times that of people younger than 65 years. The burden of medical insurance premiums is largely dependent on the working-age population, which is thought to have increased disparities between generations.

\section{The largest challenge of this super-aged society}

To analyse the largest challenge in this aging society, four main factors will be discussed: (1) government funding; (2) human resources; (3) effectiveness of the current healthcare policies; and (4) a sense of solidarity.

\section{Government funding}

Figure 5 shows the future projection for social security costs. In 2018 , the social security cost of 121.3 trillion yen is expected to increase to about 190 trillion yen in 2040, and its share of GDP is expected to increase from 21.5 percent to 24.0 percent. The largest share of social security costs is pensions and medical expenses, which account for three-quarters of the total.

With regard to the increasingly social security costs, the problem of pensions is inevitable. The government created the "100-year Relief Pension Plan" in 2004, in which the government rather than beneficiaries are provided with relief (Kato, 2019). Pension consists of two parts: capitation-based part and income-based part. The funding for the capitation-based part comes from taxation, even though social insurance is applied in general in Japan. Taxation contributions have been increased from 33 percent to 50 percent of the funding. This is

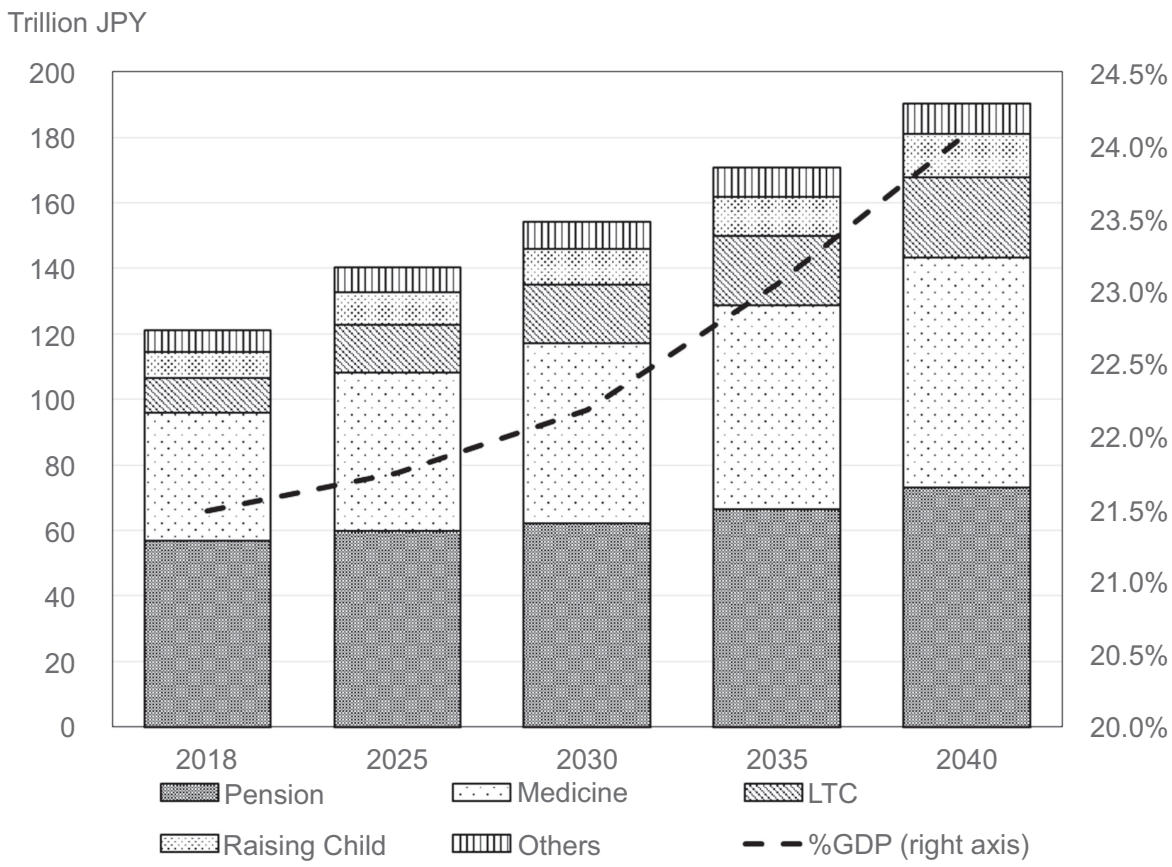

Source: Ministry of Health, Labour and Welfare (2018b)

Figure 5. Predicted social security costs 
PAP

23,3

266

support for contributions by young active generations to pay basic pension costs, and it is a measure to secure stable financial resources for basic pension. The macro-slide system, reflecting economic growth, and a premium ceiling (18.7 percent of income) were also introduced, in which the pension funds can be adjusted so that the total payment will be less than the financial resources determined by the economic growth rate and payers' income. Moreover, in order to prevent pension fund exhaustion, it appears necessary to delay the age of starting pension payments. In the current Japanese system, the pension age is 65 years; whereas, the age in the United States is 67 years, in Germany is 67 years, in the UK is 68 years, and in 19th century Germany, when the public pension system was first established, payment started from 70 years. Raising the pension age is a matter of considerable debate. In addition, the government requests that companies delay the retirement age and it encourages the elderly to continue working.

\section{Human resources}

The human resources shortage is another major problem in a super-aged society. Figure 6 predicts the required amount of human resources required for healthcare, nursing, and other elderly welfare. The line graph shows the change in the percentage of healthcare and welfare human resources for all employees. Figure 7 shows how the number of healthcare workers has increased and about $40 \%$ of new adults are engaged in healthcare. Although the number of healthcare workers has already increased significantly, it is expected that more will be needed in the future, and the shortage of human resources will become one of the major problems.

\section{Effectiveness of the current healthcare policies}

Under these circumstances, the demand for improvements in medical and LTC effectiveness has been increasing. In 2018, the reform plan for medical and LTC services was finalized, with the aim of improving the effectiveness of medical and LTC services by 5 percent. In terms of concrete plans, there are currently four items: (1) promotion of robots, artificial intelligence,

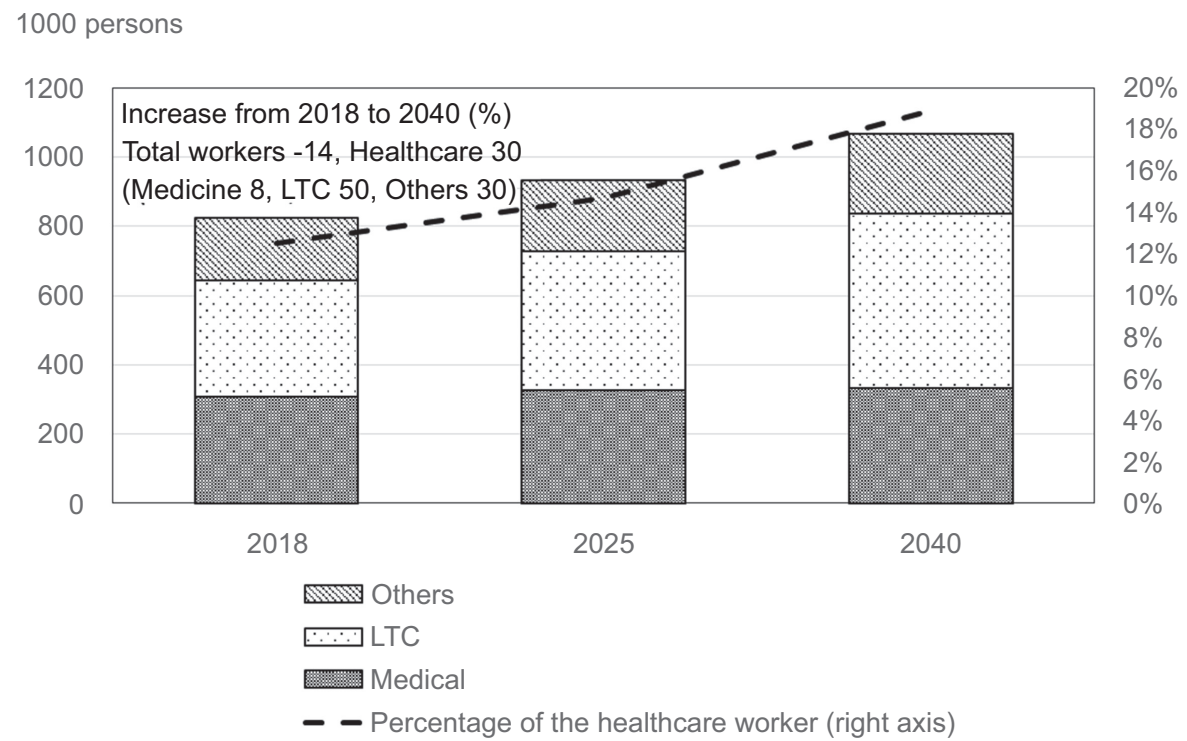

Shortage of human resources

Source: Ministry of Health, Labour and Welfare (2018b) 


\section{Social and health sector reform in Japan}

300

250

200

150

100

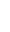

\section{(1)}

Source: Ministry of Health, Labour and Welfare (2019b)

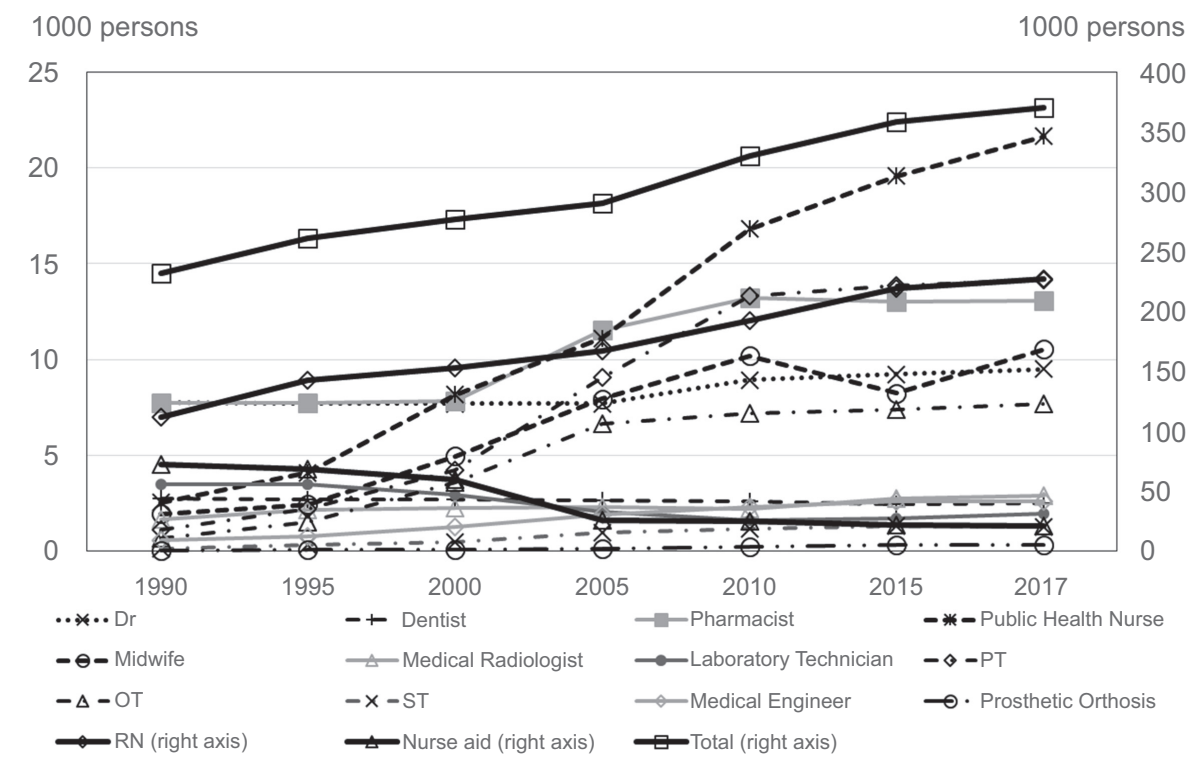

and ICT, including data health reform; (2) developing human resources by task shifting/ sharing and promoting the use of senior human resources; (3) organizational management reform; and (4) expansion of service providers and promotion of collaboration. However, to define the output of healthcare, of which LTC comprises a significant portion, is quite difficult. With the growing importance of chronic care and home health care, which are labor intensive, improved effectiveness is expected in limited areas, such as remote medicine, monitoring, and primary prevention.

In pursuit of medical efficiency, it is necessary to measure outputs and inputs and to estimate how many health services are needed in the community. It is difficult to estimate how much medical care will be needed. How to measure demand, including medical treatment and LTC in the chronic phase, has not been well established. As an example of a method of estimating demand in a region, the authors proposed the Comprehensive Cost of Illness (C-COI) method (Matsumoto et al., 2017; Matsumoto and Hasegawa, 2019; Hirata et al., 2019). C-COI is a method of calculating the social burden of a disease, including the burden of medical care and the burden of LTC. It consists of medical direct costs (MDC; annual medical expense), morbidity costs (MbC; loss of labor value caused by treatment of a disease), mortality costs (MtC; loss of human capital value), LTC direct costs (LTC costs covered by public LTC insurance), and informal care costs (family burden of LTC). C-COI is defined as follows:

$$
\mathrm{C}-\mathrm{COI}=\mathrm{MDC}+\mathrm{MbC}+\mathrm{MtC}+\mathrm{LTC} \text { direct costs }+ \text { informal care costs }
$$

Figure 8 shows the per capita C-COI of cerebrovascular diseases in 47 prefectures, which are also the main actors of the Regional Medical Plan and Regional Medical Vision. The prefecture with the highest C-COI per capita (Kochi) is approximately 1.71 times that of the smallest (Aichi). Although Japan has achieved universal coverage, and access to health care among regions should be less variable than in other countries, C-COI per capita still varies widely. Also, the composition ratios of C-COIs vary; for example, the prefecture with the 


\section{8}

Figure 8.

C-COI of cerebrovascular diseases in 47 prefectures
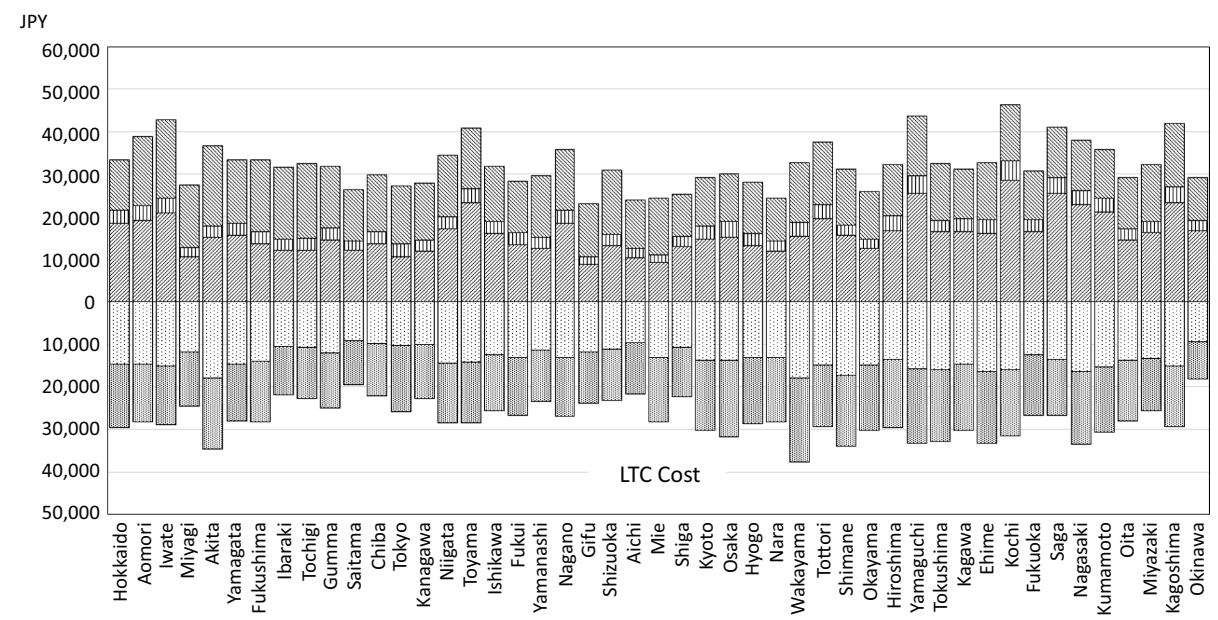

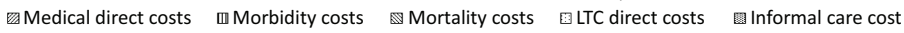

Sources: Compiled from data extracted from e-Stats (2020), including Patient Survey, Vital Statistics, Survey of National Medical Care Insurance Services, Basic Survey on Wage Structure, Labor Force Survey, Estimates of Monetary Valuation of Unpaid Work, Comprehensive Survey of Living Conditions, and Statistics of LTC Benefit Expenditures.

highest proportion of LTC costs (LTC direct costs + informal care costs) (Okayama) accounts for 53.9 percent, whereas that with the lowest (Okinawa) is 38.4 percent. Medical needs should be noted, considering the difference in social burden of such diseases, in order to provide medical care services with an emphasis on the health care user's perspective.

Healthcare is expected to change significantly in 2040. Table 2 summarizes this change in paradigm. The aim of care will change to "care management" from "cure disease," and the role of the physician will be as manager of a medical team. New concepts and a consensus will be needed regarding quality and safety assurance, as well as for establishing evidence.

\section{A sense of solidarity}

A sense of solidarity has become the final but critical factor in supporting a super-aged society. The sense of solidarity within the same generation and the solidarity amongst different generations are both important. The introduction of effective but expensive medical technologies has made it possible to treat diseases that had previously been incurable. Japanese public medical insurance covers almost all medical technologies, irrespective of

\begin{tabular}{lll}
\hline & 2020 & 2040 \\
\hline Aim of care & Cure of disease & Management of care \\
Target of care & Acute disease, trauma & Chronic disease \\
No of conditions & Single & Multiple \\
Treatment options & Choose one most effective & Multiple treatments according to patients' \\
& treatment & preference and timeline \\
No of providers & Single & Multiple \\
Evidence & Randomized controlled trial & Big data \\
establishment & & \\
\end{tabular}

Table 2.

Paradigm shift from "cure disease" to "care management" toward 2040 
their cost. The cost of newly developed technologies is skyrocketing, and it is not certain whether this policy can continue. Access to healthcare could be limited, especially among the poor or elderly when expensive treatments are not fully covered by medical insurance. Japanese society is not accustomed to this situation and it could reduce the sense of solidarity.

From the Japanese experience, it can be learnt that aging has caused various problems. First, in terms of financial resources, pension costs might be as important as care costs. It is important to delay the age at which pensions can be received and to support employment to the age of 65-74. In terms of human resources, as modernized care requires more varied specialists, it can be the most serious challenges. As for healthcare effectiveness, with the growing importance of chronic care and home health care, improved effectiveness is expected only in limited areas, such as remote medicine, monitoring, and primary prevention. Finally, it is necessary to consider the impact of disparities in access to healthcare services on social solidarity. Among these, the shortage of human resources and a sustained sense of solidarity appear to be the most important areas for further consideration.

\section{Conclusion}

Japan has experienced rapid aging and is one of the most rapidly aging countries in the world. Since the mid-1980s, the health sector reform has been underway to build a better healthcare system and hence support a super-aged society. The circumstances of health sector reform as well as the purpose should be noted. The Japanese experience has shown that a kind of Community-based Integrated Care System is essential, particularly to be considered from the perspective of health care users. As a super-aged society, it is critical for Japan to have more consensus to further remove potential obstacles, paying attention to the change of paradigm and the purpose of care. The most important challenges to a continuously aging society tend to be the lack of medical staff and also the maintenance of a sense of solidarity throughout the whole society. The influence of COVID-19 pandemic is to be investigated in future, but local governments would be willing to play an important role in healthcare delivery, and this kind of commitment is needed in a super-aged society. In a long run, this paper is expected to serve as a pioneer or at least a reference for other East Asian countries that would encounter the aging problem after Japan in the $21^{\text {st }}$ century.

\section{References}

Cabinet Office (2019), White Paper on Population Aging 2019, Nikkei, Tokyo.

e-Stats (2020), "Japan in Statistics", available at: https://www.e-stat.go.jp/ (in Japanese) (accessed 16 March 2020).

Hasegawa, T. (2020), "Health sector reform in Japan", in Hu, T., et al. (Eds.), Health Care Policy in East Asia: A World Scientific Reference, World Scientific, Singapore.

Hirata, K., Nagahama, T., Kitazawa, T., Matsumoto, K. and Hasegawa, T. (2019), "Cost of illness of cerebrovascular disease in each prefecture of Japan", Journal of the Japan Society for Healthcare Administration, Vol. 56 No. 4, pp. 5-12.

Kato, H. (2019), "The 100-year life and public pension reform", The Japan Times, 14 February, available at: https://www.japantimes.co.jp/opinion/2019/02/14/commentary/japan-commentary/ 100-year-life-public-pension-reform/\#.Xp_PVplUtdg (accessed 16 March 2020).

Matsumoto, K., Hanaoka, S., Wu, Y. and Hasegawa, T. (2017), "Comprehensive cost of illness of three major diseases in Japan”, Journal of Stroke and Cerebrovascular Diseases, Vol. 26 No. 9, pp. 1934-1940.

Matsumoto, K. and Hasegawa, T. (2019), "Comprehensive cost of illness: a novel method to evaluate economic burden of disease in a superaged society", Toho Journal of Medicine, Vol. 5 No. 1 , pp. 7-12. 
PAP

23,3
Ministry of Health, Labour and Welfare (2002), "Long-term care insurance in Japan", available at: https://www.mhlw.go.jp/english/topics/elderly/care/ (accessed 16 March 2020).

Ministry of Health, Labour and Welfare (2012), "About medical system to affect five diseases, five medical services and home health medical care", available at: http://dl.med.or.jp/dl-med/doctor/ report/kacho.pdf (in Japanese) (accessed 16 March 2020).

Ministry of Health, Labour and Welfare (2015), "Japan 2035: leading the world through health", available at: https://www.mhlw.go.jp/seisakunitsuite/bunya/hokabunya/shakaihoshou/ hokeniryou2035/assets/file/healthcare2035_proposal_150703_summary_en.pdf (accessed 16 March 2020).

Ministry of Health, Labour and Welfare (2016), "Example of efforts toward the construction of the community-based integrated care system", available at: https:/www.mhlw.go.jp/stf/ seisakunitsuite/bunya/hukushi_kaigo/kaigo_koureisha/chiiki-houkatsu/ (in Japanese) (accessed 16 March 2020).

Ministry of Health, Labour and Welfare (2017a), "Statistics of long-term care benefit expenditures", available at: https://www.e-stat.go.jp/stat-search?page $=1 \&$ kikan $=00450$ (in Japanese) (accessed 16 March 2020).

Ministry of Health, Labour and Welfare (2017b), "Establishing the community-based integrated care system”, available at: https:/www.mhlw.go.jp/english/policy/care-welfare/care-welfare-elderly/ index.html (accessed 21 April 2020).

Ministry of Health, Labour and Welfare (2018a), "Documents for the headquarter meeting for social security and work style reforms for the year 2040", available at: https:/www.mhlw.go.jp/stf/ shingi/other-syakaihosyou_306350_00001.html (in Japanese) (accessed 21 April 2020).

Ministry of Health, Labour and Welfare (2018b), "Future outlook for social security in anticipation of 2040 (material for discussion)", available at: https://www.mhlw.go.jp/stf/seisakunitsuite/bunya/ 0000207382_00001.html (in Japanese) (accessed 21 April 2020).

Ministry of Health, Labour and Welfare (2019a), "National medical care expenditure", available at: https://www.e-stat.go.jp/stat-search?page $=1 \&$ kikan $=00450$ (in Japanese) (accessed 21 April 2020).

Ministry of Health, Labour and Welfare (2019b), White Paper on Annual Health, Labour and Welfare, Nikkei, Tokyo.

Ministry of Internal Affairs and Communication (2016), "Population census", available at: https:// www.e-stat.go.jp/stat-search?page $=1 \&$ toukei $=00200521 \&$ kikan $=00200$ (in Japanese) (accessed 21 April 2020).

Ministry of Justice (2019), "Statistics of foreign people living in Japan", available at: https://www.e-stat. go.jp/stat-search/files?page $=1 \&$ layout $=$ datalist $\&$ touke $i=00250012 \&$ tstat $=000001018034 \&$ cycle $=1 \&$ year $=20190 \&$ month $=24101212 \&$ tclass $1=000001060399$ (in Japanese) (accessed 8 August 2020).

Morikawa, M. (2014), "Towards community-based integrated care: trends and issues in Japan's longterm care policy", International Journal of Integrated Care, Vol. 14 No. 1, pp. 1-10.

Song, P. and Tang, W. (2019), "The community-based integrated care system in Japan: health care and nursing care challenges posed by super-aged society", BioScience Trends, Vol. 13 No. 3, pp. 279-281.

Statistics Bureau, Ministry of Internal Affairs and Communications with collaboration of Ministries and Agencies (2020), "Portal site of official statistics of Japan", available at: https://www.e-stat. go.jp/ (in Japanese) (accessed 21 April 2020).

United Nations (Department of Economic and Social Affairs Population Division) (2015), "World population ageing 2015", available at: https:/www.un.org/en/development/desa/population/ publications/pdf/ageing/WPA2015_Report.pdf (accessed 16 March 2020).

United Nations (2019), “World population prospects 2019”, available at: https://population.un.org/wpp/ (accessed 16 March 2020). 


\section{About the authors}

Tomonori Hasegawa, MD, PhD, is Professor of the Department of Social Medicine, Toho University, School of Medicine. His academic expertise covers health policies and performance evaluation of health systems. He published more than 180 reviewed papers and about 100 books. He was engaged in health sector reform in Japan as an advisory member of the Cabinet Office (2001-2010). He is an executive board member of the Japan Council for Quality Health Care, a board member of the Japanese Society of Healthcare Management, Editor-in-Chief of the Journal of Japanese Healthcare Management. Tomonori Hasegawa is the corresponding author and can be contacted at: tommie@med.toho-u.ac.jp

Kunichika Matsumoto, PhD, is Associate Professor of the Department of Social Medicine, Toho University, School of Medicine. He graduated from Department of Social Science Waseda University in 1991, and graduated from Graduate School of Social Sciences, Waseda University in 1994. His academic activities cover health policies, health economics and development economics.

Ryo Onishi, MMG, is Assistant Professor at the Department of Social Medicine, Toho University, School of Medicine. He graduated from Keio University School of Bachelor of Arts in Policy Management in 2006, and Keio Graduate School of Media and Governance in 2018. His academic activities cover health policies and health economics. He worked as a public officer at Kyoto prefecture, and the Kyoto Medical Career Support Center from 2017 to 2018.

Koki Hirata, $\mathrm{MD}$, is $\mathrm{PhD}$ candidate at the Department of Social Medicine, Toho University, Graduate School of Medicine. He graduated from Toho University School of Medicine in 2016 and had residency at Toho University Ohashi Medical Center (2016-2018).

For instructions on how to order reprints of this article, please visit our website: 